\title{
Association Between Surgical Margin Status and Local Recurrence in Iranian Patients Suffering from Colorectal Cancer
}

\author{
Narges Sistany Allahabadi (iD ${ }^{1,}$, , Hossein Yahyazadeh (iD ${ }^{1,}{ }^{* *}$, Hossein Pourtavakoli ${ }^{1}$, Azita \\ Abdollahinejad ${ }^{1}$ and Marzieh Beheshti ${ }^{1}$ \\ ${ }^{1}$ Clinical Cancer Research Center, Milad General Hospital, Tehran, IR Iran \\ "Corresponding author: Clinical Cancer Research Center, 12th floor, Milad General Hospital, Hemmat Highway, Tehran, Iran. Email: nickpier1990@gmail.com \\ "Corresponding author: Clinical Cancer Research Center, Milad General Hospital, Tehran, Iran. Email: hyahyazadeh@gmail.com
}

Received 2018 August 07; Revised 2018 October 02; Accepted 2018 October 13.

\begin{abstract}
Background: Colorectal cancer is a highly prevalent cancer around the world and Iran. There are different criteria that can affect the survival rate of this disease. Surgical margin status is one of these criteria; there are still challenges about how it can change the surveillance of the disease.

Objectives: In this study, we assessed the relativity between surgical margin status and the stage of disease in Iranian patients suffering from colorectal cancer.

Methods: This is an observational cross-sectional study. A total of 797 patients with colorectal cancer were included and a checklist of demographic, clinical, and pathological data was filled for each one. Based on the pathology result of the biopsy, the patients were divided into different histological groups. Surgical margin status was defined individually. To declare the relativity between surgical margin status and independent variables, we used Spearman's rho test.

Results: The stage of the disease and its histological type and grade were significantly correlated. There was also a significant correlation between histological grade and type of the disease.

Conclusions: Surgical margin status and stage of the disease are challenging prognostic factors in disease recurrence and survival. The patients who participated in this study had meanly higher age and stage of diagnosis than earlier studies either global or local. It can be due to a lack of a systematic program for early detection of CR cancer in Iran that emphasizes the necessity of GI screening systems.
\end{abstract}

Keywords: Neoplasm, Colorectal Tumor, Iran

\section{Background}

Nearly 1.4 million people were suffering and 693900 died from colorectal cancer (CRC) in 2012 around the world. It is the third common cancer among men and the second one among women, but its overall prevalence is higher in men. It is more prevalent in whites. Australia/New Zealand, Europe, and North America have the highest and Africa and South Central Asia have the lowest incidence rate around the world (1). In Iran, the third leading cause of death is cancer and gastrointestinal cancers are the second prevalent ones $(7 / 100000)(2,3)$. The median survival of CRC is 30 month, but there are different prognostic factors that affect the survival rate of the patients like early detection, chemotherapy, clinical and histological factors, pathological grading, primary localization of the tumor, and number of metastatic sites (4). One of the criteria that improves the prognosis is complete resection of tumoral surgical margins (5). Resection of 1-centimeter (cm) margin is the gold standard of liver metastatic colorectal resection (6). However, there are a number of surgical factors that can alter the results and patient's survival rate. In this study, we attempt to assess the relativity among surgical margin status and the stage of disease in Iranian patients suffering from CRC.

\section{Methods}

This is an observational cross-sectional uni-center study to assess the clinical and pathological characteristics of patients with colorectal cancer during 2009 to 2015 in Tehran. All the patients with pathological diagnosis of CRC based on pathologist diagnosis by non-probable judgmental sampling method were included in the study and all the patients, who received only chemotherapy or partitive care or had tumor surgery in another center, were 
excluded. A checklist including 88 variable about the demographic and clinical and pathological factors was filled by the pathology specialist after performing the surgery by surgeon. Based on the pathology result of the biopsy, the patients were divided into mucinous and non-mucinous adenocarcinoma groups and histologically arranged in 4 different grade; grade I: Well-differentiated, grade II: Moderately differentiated, grade III: Poorly differentiated and grade IV: Non-differentiated. The patients were staged in 10 different stages according to TNM Classification of Malignant Tumors Staging Protocol 8th edition (T stands for primary tumor site, $\mathrm{N}$ describes regional lymph nodes that are involved, and $\mathrm{M}$ is for existence of metastasis).

Surgical margin status was defined in 11 different characteristics. All data were unanimous and coded by a random coding soft wear. No extra intervention out of National Comprehensive Cancer Network (NCCN) version 1.2018 guideline was performed for the patients and all the steps of the study were performed based on national ethical standards involving human subjects and in accordance with Helsinki Declaration of 1964 and later versions revised in 2000. All the patients who participated in the study signed the informed consent form and all data were preserved by code and anonymously. The study was conducted under supervision and approval of Milad Hospital Ethical Committee.

To analyze demographic data, we used descriptive tests like frequency and mean and to declare the relativity between surgical margin status and independent variables according to the type of our variables, we used nonparametric correlation test (Spearman's rho) by SPSS version 16. P value less than 0.05 was considered significant.

\section{Results}

A total of 797 people with CRC participated in this study, 165 (20.7\%) of whom were histologically typed as mucinous adenocarcinoma and 632 (79.3\%) were diagnosed as non-mucinous adenocarcinoma. The mean age of the patients was $59.5 \pm 13.8$ years old (male: $59.3 \pm 14.1$, female: $64.1 \pm 15.0)$. $61.7 \%$ were male and $38.3 \%$ were female. The highest prevalent diagnosing stage was IIIB (30.6\%) (Figure 1) and most of them had distal and proximal free margin (54.6\%) and were histological moderately differentiated (49.8\%) (Figure 2). Details of the demographic data are mentioned in Table 1.

Frequencies of surgical margin status in different stages of the disease are displayed in Figure 3.

In all the age groups, stage IIIB was the most prevalent one except in 30 to 40-year-old patients that were mostly diagnosed with stage IIA disease. Stage IIIB had the high-

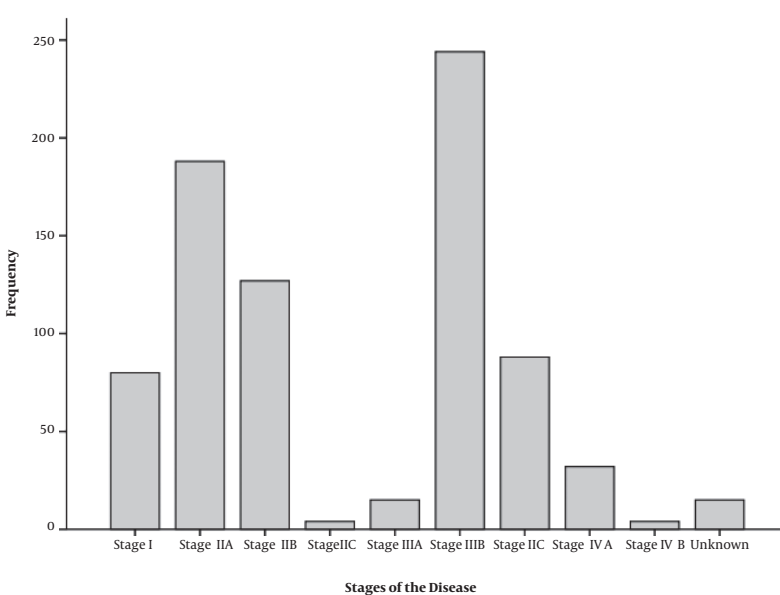

Figure 1. Frequency of different stages of CRC among participants

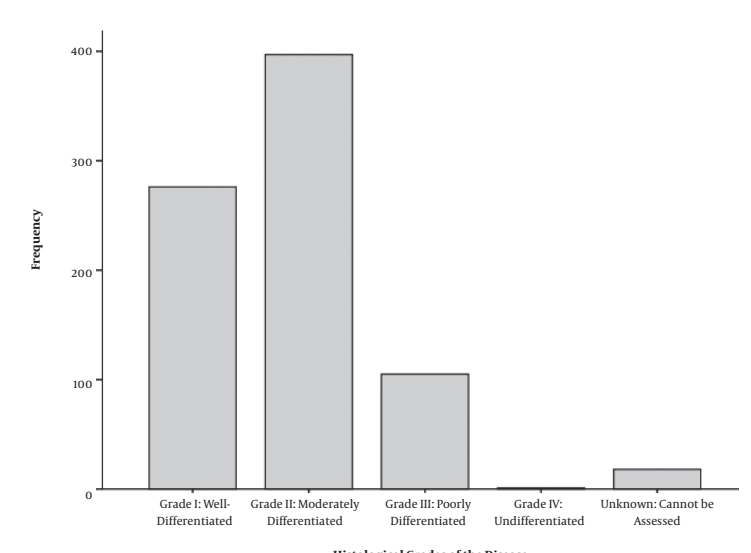

Histological Grades of the Disease

Figure 2. Frequency of different histological grade of CRC among participants

est prevalence among both female and male and also mucinous and non-mucinous patients (Table 2).

Mucinous adenocarcinoma histological type was 53.8\% more in male than female (male: $\mathrm{N}=100,12.5 \%$, female: $\mathrm{N}$ $=65,8.2 \%)$. Number of patients with non-mucinous adenocarcinoma lesion was 4.03 times more than patients with mucinous adenocarcinoma lesion $(\mathrm{N}=541,80.1 \%, \mathrm{~N}=134$, 19.9\%).

The stage of the disease and its histological type and grade were significantly correlated $(\mathrm{P}=0.02$, and $<0.0001$, respectively). There were also significant correlation between histological grade and type of the disease $(\mathrm{P}=0.04)$, but no significant correlation was observed between other variables (Table 3 ). 


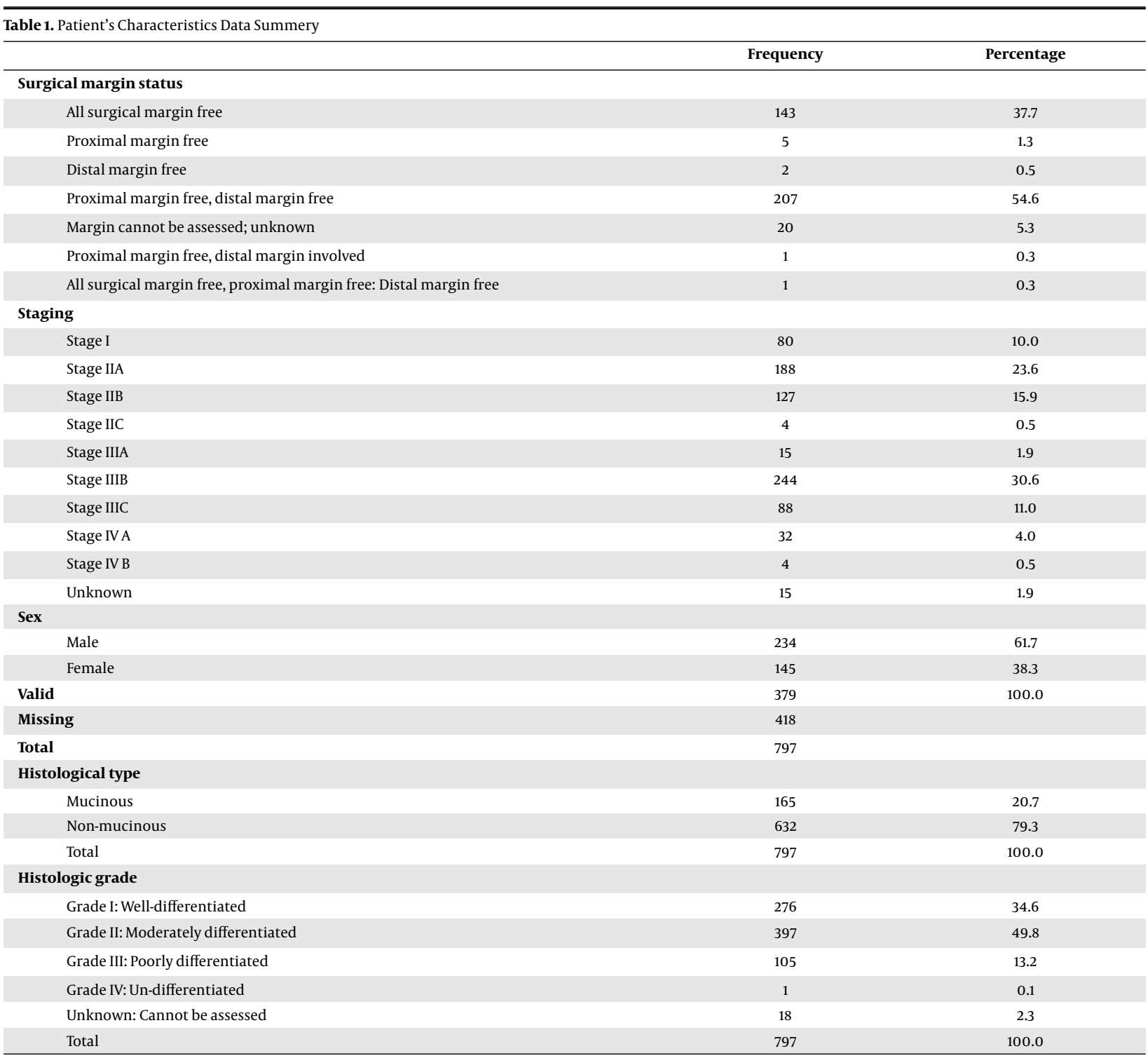

\section{Discussion}

In this assay, we have analyzed the relativity between the status of surgical margin in patients with colorectal cancer and their disease stage.

There are some known negative prognostic factors like positive surgical margin, margins $>5 \mathrm{~cm}$, multiple metastases and their site, age $>60$ years old, CEA (carcinoembryonic antigen), advance TNM stage of disease, etc. (5, 7-10).

It is not still completely clear that weather palliative or un-palliative margin resection (R1 - R2) or Ro according to Union for International Cancer Control (UICC) criteria is a more important prognostic factor or the width of surgical margins in a case that there is a tight relationship between narrow margins and extensive disease. It seems complicate to find a single surgical prognostic factor in patients with CRC $(6,9,11-16)$.

In our study, the mean age of the patients and the most prevalent stage of diagnosis was higher than earlier studies either global or local studies that can be the result of lack of systematic program for gastro-intestinal (GI) and CR cancer early detection in Iran that emphasize the necessity of GI screening systems (3,17-20).

In this study, 50 to 60 years old age group is the most populated group both in male and female that is equal to other study that was performed in 2014 in Tehran, but less than an Irish study in $2018(18,21)$.

In our survey, stage IIIB is the most populated in all 


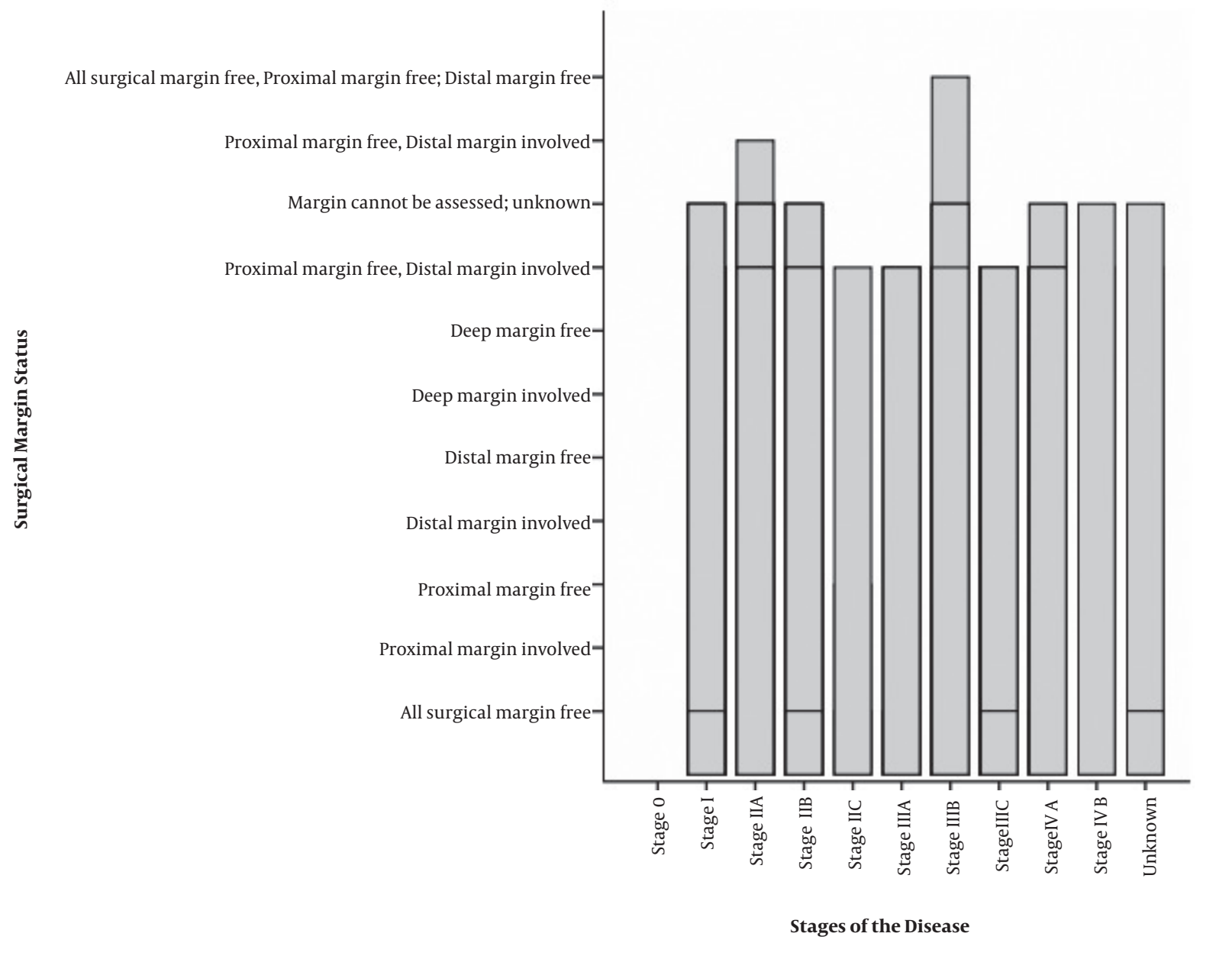

Figure 3. Frequencies of surgical margin status in different stages of CRC among participants

age groups except 30 to 40 years old group that is higher than the Irish study. And another one in 2012 in Tehran that showed stage IV is the most prevalent stage $(44.5 \%)(3,21)$.

Surgical margin status and stage of the disease are two important prognostic factors in disease recurrence and survival; there are different ideas about effectiveness of each one and some studies claim the biology of tumor and tumor factors have higher impact on survival than surgical margin status (SMS) $(11,22)$. Another study found that SMS is not directly effective on survival rate, but it is the reflection of more acute disease (15). In a study, free surgical margins was an independent prognostic factor (6) and in another one, recurrent rate was not related to margin's width (12). Some studies declare that free surgical margin is more important than the width of margins and it is related with extensive disease $(13,14,23)$. But, they both are effective on survival pattern in potentially curable patients (5). On the other hand, some studies found no significant difference among SMS and SMW and overall survival, but showed that free surgical margins independently from their width are related with patient's disease free survival $(11,24)$.

Historically, $1 \mathrm{~cm}$ margin resection was the gold standard of colorectal liver metastasis, but now there are discussions on the efficacy of $1 \mathrm{~mm}$ resection. In 2009, Vandeweyer et al. claimed that there is a significant difference in 5-year patient survival between patient with $\leq 1 \mathrm{~mm}$ and $>1 \mathrm{~mm}$ margin resection; although, their 5-year disease free survival was not significantly different (6). Another study found that $1 \mathrm{~cm}$ margin resection is the golden standard, but free surgical margin is another independent factor (12). There is also another one that say $1 \mathrm{~mm}$ surgical margin is optimum and there is no statistically difference among the survival rate of patients with free surgical margins and patients with $>1 \mathrm{~mm}$ margins (9).

In this study, the stage of the disease and its histological type and grade were significantly correlated. 


\begin{tabular}{|c|c|c|c|c|}
\hline & Histologic Grade & Surgical Margin Status & Disease Stage & Histological Type \\
\hline \multicolumn{5}{|l|}{ Histologic grade } \\
\hline Correlation coefficient & 1.000 & 0.092 & $0.203^{b}$ & $-0.071^{a}$ \\
\hline Pvalue & - & 0.064 & 0.000 & 0.046 \\
\hline $\mathrm{N}$ & 797 & 404 & 797 & 797 \\
\hline \multicolumn{5}{|l|}{ Surgical margin status } \\
\hline Correlation coefficient & 0.092 & 1.000 & -0.005 & -0.080 \\
\hline Pvalue & 0.064 & - & 0.915 & 0.110 \\
\hline $\mathrm{N}$ & 404 & 404 & 404 & 404 \\
\hline \multicolumn{5}{|l|}{ Disease stage } \\
\hline Correlation coefficient & $0.203^{\mathrm{b}}$ & -0.005 & 1.000 & $-0.108^{b}$ \\
\hline Pvalue & 0.000 & 0.915 & - & 0.002 \\
\hline $\mathrm{N}$ & 797 & 404 & 797 & 797 \\
\hline \multicolumn{5}{|l|}{ Histological type } \\
\hline Correlation coefficient & $-0.071^{\mathrm{a}}$ & -0.080 & $-0.108^{b}$ & 1.000 \\
\hline Pvalue & 0.046 & 0.110 & 0.002 & - \\
\hline $\mathrm{N}$ & 797 & 404 & 797 & 797 \\
\hline
\end{tabular}

${ }^{\mathrm{a}}$ Correlation is significant at the 0.05 level.

${ }^{\mathrm{b}}$ Correlation is significant at the 0.01 level.

There were also significant correlation between histological grade and type of the disease, but there was no significant relativity among surgical margin status histological type and grade and stage of the disease.

\subsection{Conclusions}

Surgical margin status and stage of the disease are challenging prognostic factors in disease recurrence and survival.

The patients who participated in this study had meanly higher age and stage of diagnosis than earlier studies either global or local. It can be due to lack of systematic program for early detection of CR cancer in Iran that emphasizes the necessity of GI screening systems.

\section{Acknowledgments}

None declared.

\section{Footnotes}

Authors' Contribution: None declared.

Conflict of Interests: None declared.

Financial Disclosure: None declared.

\section{References}

1. Torre LA, Bray F, Siegel RL, Ferlay J, Lortet-Tieulent J, Jemal A. Global cancer statistics, 2012. CA Cancer J Clin. 2015;65(2):87-108. doi: 10.3322/caac.21262. [PubMed: 25651787].
2. Yasemi M, Ahmadi MR, Peyman H, Yasemi MR, Khajavikhan J, Hemati K. A 7-years retrospective study of gastrointestinal cancers incidence in the western Iran. J Clin Diagn Res. 2015;9(7):EC01-5. doi: 10.7860/JCDR/2015/12003.6144. [PubMed: 26393131]. [PubMed Central: PMC4572962].

3. Mahmodlou R, Mohammadi P, Sepehrvand N. Colorectal cancer in northwestern Iran. ISRN Gastroenterol. 2012;2012:968560. doi: 10.5402/2012/968560. [PubMed: 22754700]. [PubMed Central: PMC3384951].

4. Vardanjani HM, Haghdoost A, Bagheri-Lankarani K, Hadipour M. Estimation and projection of prevalence of colorectal cancer in Iran, 2015-2020. Adv Biomed Res. 2018;7:20. doi: 10.4103/abr.abr_178_16. [PubMed: 29456991]. [PubMed Central: PMC5812060].

5. Cady B, Jenkins RL, Steele GJ, Lewis WD, Stone MD, McDermott $\mathrm{WV}$, et al. Surgical margin in hepatic resection for colorectal metastasis: A critical and improvable determinant of outcome. Ann Surg. 1998;227(4):566-71. [PubMed: 9563547]. [PubMed Central: PMC1191314].

6. Vandeweyer D, Neo EL, Chen JW, Maddern GJ, Wilson TG, Padbury RT. Influence of resection margin on survival in hepatic resections for colorectal liver metastases. HPB (Oxford). 2009;11(6):499-504. doi: 10.1111/j.1477-2574.2009.00092.x. [PubMed: 19816614]. [PubMed Central: PMC2756637].

7. Shiono S, Ishii G, Nagai K, Yoshida J, Nishimura M, Murata Y, et al. Predictive factors for local recurrence of resected colorectal lung metastases. Ann Thorac Surg. 2005;80(3):1040-5. doi: 10.1016/j.athoracsur.2004.12.033. [PubMed: 16122482].

8. Elias D, Cavalcanti A, Sabourin JC, Pignon JP, Ducreux M, Lasser P. Results of 136 curative hepatectomies with a safety margin of less than $10 \mathrm{~mm}$ for colorectal metastases. J Surg Oncol. 1998;69(2):88-93. [PubMed: 9808511].

9. Hamady ZZ, Lodge JP, Welsh FK, Toogood GJ, White A, John T, et al. One-millimeter cancer-free margin is curative for colorectal liver metastases: A propensity score case-match approach. Ann Surg. 2014;259(3):543-8. doi:10.1097/SLA.0b013e3182902b6e. [PubMed: 23732261].

10. Sun DC, Mao H, Wang ZK, Shi Y, Dai GH. [Prognostic factors of stage 3 colorectal cancer in 433 patients]. Zhongguo Yi Xue Ke Xue Yuan Xue Bao. 2015;37(5):549-56. Chinese. doi: 10.3881/j.issn.1000503X.2015.05.010. [PubMed: 26564506]. 
11. Margonis GA, Spolverato G, Kim Y, Ejaz A, Pawlik TM. Intraoperative surgical margin re-resection for colorectal liver metastasis: Is it worth the effort? J Gastrointest Surg. 2015;19(4):699-707. doi: 10.1007/s11605014-2710-2. [PubMed: 25451734].

12. Poultsides GA, Schulick RD, Pawlik TM. Hepatic resection for colorectal metastases: The impact of surgical margin status on outcome. HPB (Oxford). 2010;12(1):43-9. doi: 10.1111/j.1477-2574.2009.00121.x. [PubMed: 20495644]. [PubMed Central: PMC2814403].

13. Elias D, Cavalcanti A, Sabourin JC, Lassau N, Pignon JP, Ducreux M, et al. Resection of liver metastases from colorectal cancer: The real impact of the surgical margin. Eur J Surg Oncol. 1998;24(3):174-9. [PubMed: 9630855].

14. Hou RM, Chu F, Zhao J, Morris DL. The effects of surgical margin and edge cryotherapy after liver resection for colorectal cancer metastases. HPB (Oxford). 2007;9(3):201-7. doi: 10.1080/13651820701275113. [PubMed: 18333223]. [PubMed Central: PMC2063602].

15. Truant S, Sequier C, Leteurtre E, Boleslawski E, Elamrani M, Huet G, et al. Tumour biology of colorectal liver metastasis is a more important factor in survival than surgical margin clearance in the era of modern chemotherapy regimens. HPB (Oxford). 2015;17(2):176-84. doi: 10.1111/hpb.12316. [PubMed: 25041611]. [PubMed Central: PMC4299392].

16. Me A, Akbari M, Zirakzadeh H, Nafissi N, Heidari A, Hosseinizadegan Shirazi F. Margin status influence on the outcome of patients treated with breast conserving surgery. Iran J Cancer Prev. 2011;4(4):177-82. [PubMed: 26322195]. [PubMed Central: PMC4551288].

17. Soriano LC, Soriano-Gabarro M, Garcia Rodriguez LA. Trends in the contemporary incidence of colorectal cancer and patient characteristics in the United Kingdom: A population-based cohort study using The Health Improvement Network. BMC Cancer. 2018;18(1):402. doi: 10.1186/s12885-018-4265-1. [PubMed: 29636012]. [PubMed Central:
PMC5894203].

18. Sohrabi M, Zamani F, Ajdarkosh H, Rakhshani N, Ameli M, Mohamadnejad M, et al. Prevalence of colorectal polyps in a group of subjects at average-risk of colorectal cancer undergoing colonoscopic screening in Tehran, Iran between 2008 and 2013. Asian Pac J Cancer Prev. 2014;15(22):9773-9. [PubMed: 25520103].

19. Iravani S, Kashfi SM, Azimzadeh P, Lashkari MH. Prevalence and characteristics of colorectal polyps in symptomatic and asymptomatic Iranian patients undergoing colonoscopy from 2009-2013. Asian Pac J Cancer Prev. 2014;15(22):9933-7. [PubMed: 25520131].

20. Pahlavan PS, Kanthan R. The epidemiology and clinical findings of colorectal cancer in Iran. J Gastrointestin Liver Dis. 2006;15(1):15-9. [PubMed: 16680227].

21. Ullah MF, Fleming CA, Mealy K. Changing trends in age and stage of colorectal cancer presentation in Ireland - From the nineties to noughties and beyond. Surgeon.2018. doi: 10.1016/j.surge.2018.03.006. [PubMed: 29680182]

22. Choi JH, Yoon MH. Hepatic resection margin predicts survival in colorectal cancer with hepatic metastasis. Korean J Hepatobiliary Pancreat Surg. 2012;16(2):55-8. doi: 10.14701/kjhbps.2012.16.2.55. [PubMed: 26388907]. [PubMed Central: PMC4574986].

23. Liu W, Sun Y, Zhang L, Xing BC. Negative surgical margin improved long-term survival of colorectal cancer liver metastases after hepatic resection: A systematic review and meta-analysis. Int J Colorectal Dis. 2015;30(10):1365-73. doi: 10.1007/s00384-015-2323-6. [PubMed: 26198997].

24. Herman P, Pinheiro RS, Mello ES, Lai Q, Lupinacci RM, Perini MV, et al. Surgical margin size in hepatic resections for colorectal metastasis: Impact on recurrence and survival. Arq Bras Cir Dig. 2013;26(4):309-14. [PubMed: 24510040] 


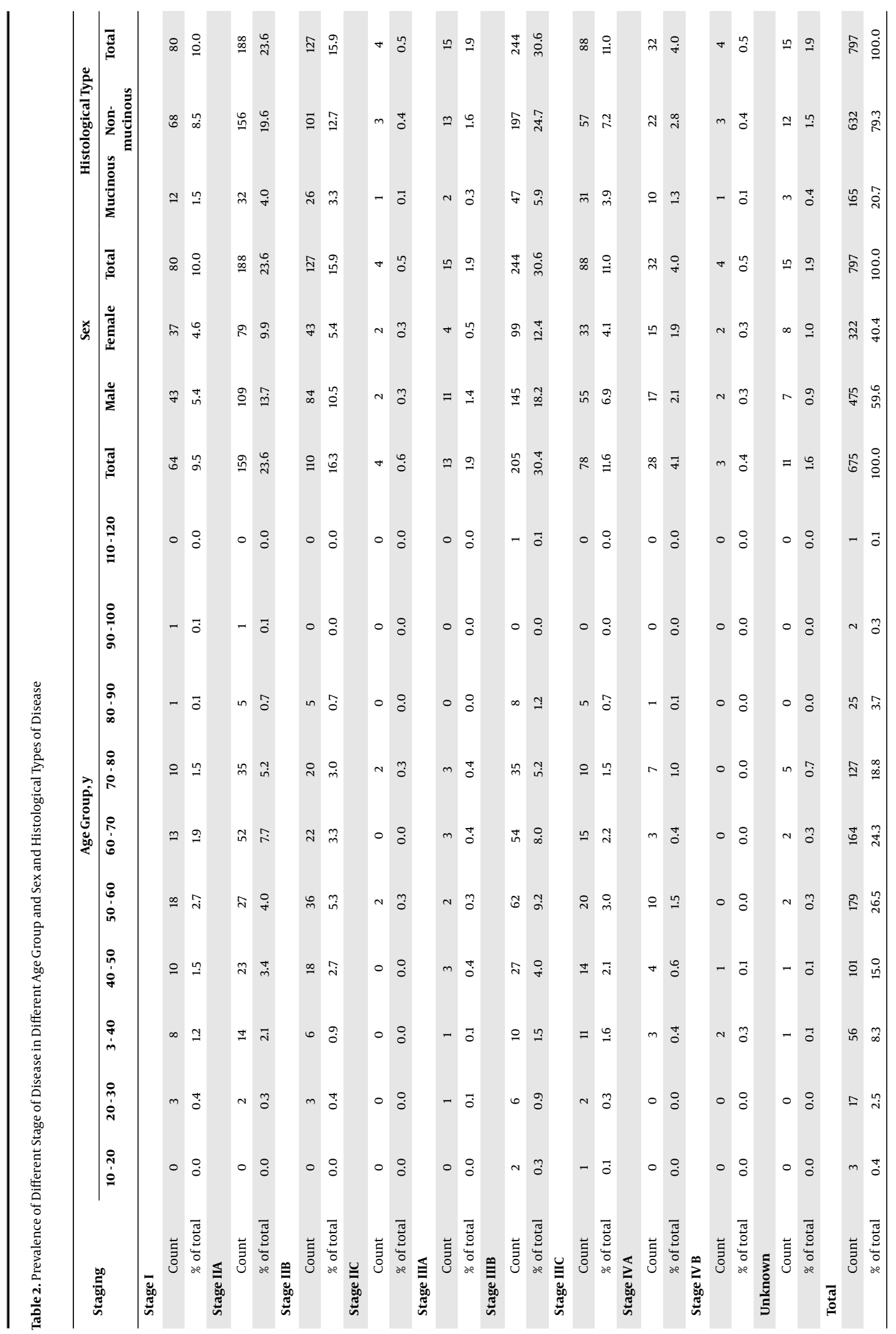

